\title{
OBSERVATION: THEORY-LADEN, THEORY-NEUTRAL OR THEORY-FREE?
}

Article in The Southern Journal of Philosophy · March 2010

Dol: 10.1111/:2041-6962.1976.tb01305.x

1 author:

William Rottschaefer
Lewis \& Clark College

56 PUBLICATIONS 176 CITATIONS

SEE PROFILE

Some of the authors of this publication are also working on these related projects:

Project Philosophy of Biology View project

Project Science and Religion View project 
The

Southern Journal of

Philosophy

Volume XIV, Number 4

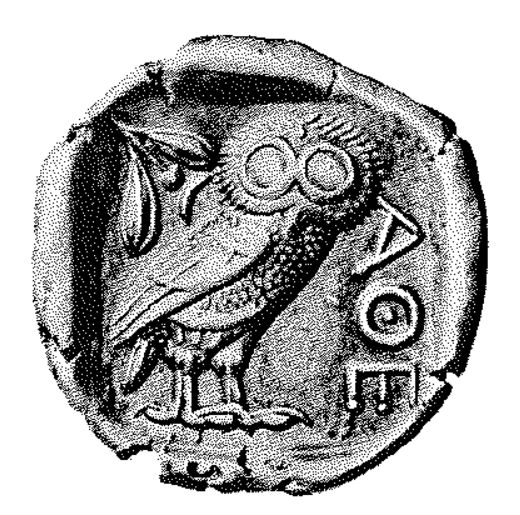


THE SOUTHERN JOURNAL OF PHILOSOPHY

Editor: Nancy D. Simco

Managing Editor: Gene G. James

\section{Ronald H. Epp, David R. Hiley, Peter Barker}

Billy M. Jones, Jerry N. Boone, Walter R. Smith, James D. Simmons ADVISORY EDITORS

E.M. Adams

University of North Caroling

John P. Anton

Emory University

Edward G. Ballard

Richard L. Barber

University of L Louisville

William B. Barton, $J_{r}$

Memphis. State University

Charles P. Bigger

Louisiana State University

W.T. Blackstone

University of Georgia

Douglas Browning

James Collins

St. Louis University

Richard T. DeGeorge

Iredell Jenkins
Insity

University of Alabam

John Lachs

Vanderbilt Universit

Ramon Lemos

University of Miam

James W. Oliver

Dwight Van de Vate, J.

wit. Werk mister

Furida State University

Anthony Woozley

Univerity of

Richard M. Zaner
Southern. Methodist University

The Southern Journal of Philosophy is published quarterly by the Department of Philosophy, Memphis State University. The journal is intended as a forum for the expression of philosophical ideas, and the editors welcome papers written from all philosopical perspectives. The annual subscription rate is $\$ 4.00$ to students, $\$ 8.00$ to individuals and $\$ 12.00$ to libraries and other institutions. Prices for single copies and back issues are avaliable on request. All correspondence should be sent to The Southem Joumal of Phllosophy, Memphis State University. Manuscripts as adopted by the Association of Editors of Philosophy Journals. Manuscripts to be considered for publication should be submitted to The Editor articles printed in the journal. Return postage must accompany all manuscripts.

Copyright 1976 The Southern Journal of Philosophy
OBSERVATION: THEORY-LADEN,

OHEORY-NEUTRAL OR THEORY-FREE?

William A. Rottschaefer

Lewis and Clark College

One major area of discussion in recent philosophy of science has been the distinction between observation and thoory. The well entrenched logical positivistempiricist orthodoxy, what I shall call the Old Empiricism, has maintained that there is some kind of substantive widely attacked recently and has been seriously undermined ${ }^{2}$ as been orthodoxy, what I shall call the New Empiricism, seems to be emerging ${ }^{3}$ This position views the distinction between observation and theory as pragmatic and relative. Old Empiricist responses have for the most part conceded major points to their foes. Thus the view that theories are theories are tested by observations is being replaced by the view that with theories neutral to the theory being tested. The positions laden radical critics of the Old Empiricists that each theory has its own set of observation statements and thus cannot be tested by observations has been shown to be incorrect.

Most of these developments, I believe, have been healthy; but they have tended to obscure an important, substantive distinction between less implicitly argued for this over-looked distinctionce ${ }^{6}$ In this more or will argue that there is a substantive distinction between observation and theory. Secondly, such a distinction does not involve the problems which the Old Empiricist formulation encountered. Thirdly, it is compatible with the approaches of the New Empiricism, incorporating their criticism of both the Old Empiricists and their radical critics. Finally, this substantive distinction helps to sort out several issues which ry and observation. The important (I) 1 believe, are the following: drawn from a theory-independent source, empirical observation, an

(2) Truth-yalue Independence: The truth value of observational

William A. Rottschaefer is Assistant Professor of Philosophy at Lewis and Clark

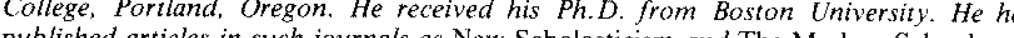
Much of his research and writing has focused on problems connected with the relationsh of scientific theory art 
statements is ascertained from a theory-independent source, empirical observation, and thus is independent of the truth values of any theory. (3) Incorrigibility. Some empical se distinct from the corrigible direct contact with what is the case, incorrigible foundation for the statements of theory. They pr

(4) Factualness: Some statements put us in direct contact with wat is the case. Theories do so only indirectly, if they do so at all.

(5) Use in Perceptual Reports: Observational statements and predicates are those used in
statements and predicates are not so used.

(6) Non- protlon Function Observational statements are explained by theoretical statements and do not themselves explain. (7) Ordinary Language: The realm of ordinary language is a logically independent realm which is entirely adequate in itself and can in no way be affected by the logically distinct realms of scientilic discourse.

The radical attack led by Hanson, Kuhn, and Feyerabend on these bases for a distinction between theory and observation is usially developed in the context of giving an account of the growtific theories. The radicals have argued in various ways.

(8) Radical Meaning Dependence The meaning of observational terms is dependent upon the theory which is designed to explain them. Thus competing theorics each have wer is because of this they bese task of giving an alternative account of

theoretical change.
(9) Radical Truth-Value Dependence: The truth-value of empirical (9) Rat is a function of the truth-value of the theories from which they derive and upon which they are dependen

(10) In-Principle Corrigibilly. No observational statement is incorrigible, for, indeed, they are all theory-lad

(11) Rejection of Givenness: There are no statements which put us in direct contact with what is the case.

(12) Use of Theory in Perceptual Reports: Theoretical statements and predicates can be and are used in perceptual reports.

Observation: Just as lower level theories are explained by higher lever ins statements are possible theries.

The reply to the radical critics has been aimed at saving the rational character of scientific endeavour while granting that the sharp distinction between observation and theory cannot be main taiss theoryit has been argued that though all observations are more or hess theoryis a pragmatic one and relative to a particular context, nevertheles to observational tests. This is potions and competing theories can be put theory-free observations but by theory-neutral observations, that is to say, by observations which, though dependent on theories, are not dependent on the theories under question. A new orthodoxy seems to be Principle Corrigibility, (11) Rejection of Give Old Empiricism (10) Inin Perceptual Reports, (13) Theory-like Function of Observ of Theory against the Radicals it argues

(14) Relevant Meaning Independence: Though the meaning of observational statements is dependent upon theories and / or laws and is not the direct result of sensory input, nevertheless the meaning of the terms in the test statements need not and, indeed, must not be dependent (15) Relevant Truth-Value Independence. And though.

observational statements is theory-dependent and is direct contact with what is the case, nevertheless the truth of the test statement need not and, indeed, must not depend on the truth of the statements of the theory under scrutiny.

I shall now point out some unsatisfactory aspects of the New and then sketch an alternative account which observation and theory maintain a substantive distinction between theory and possible to while both avoiding the Old Empiricist pitfalls and accepting the valid points of the Radical Critics and the New Empiricists.

Mary Hesse and Peter Achinstein, among others, are prominent critics of both the Old Empiricism and its radical foes. It will be helpful between theory and their arguments against a substantive distinction Achinstein's basic argument agan

that there is no single unique waych a substantive distinction is observation. He concludes that the distinction is a relative, contextdependent one which points up a number of useful contrasts.

For example, he argues against Carnap's account of the distinction on are not According to properties which are observable and those which what is observed in a given situation. For what is in way of describing the observational description can become in another context part of theoretical description. Thus the same scientist can talk of seeing the proton following a pah hiverging from the horizontal or he can argue that the observed rising line of bubbles indicates the path of the unobservable proton.
But this kind of arg

conclusive. Achinstein is quite right in scientific discourse in which theoretical description ordinary an perceptual reports. And he has done a service by his used in 
classification of such usages. But careful observation and classification are only the first steps in an adequate account of a phenomenon. maintain that in philosophical inquiry, as in the natural and social sciences, observation and classification ought to be supplemented by nor even be able to find one. But to argue that the distinction is not unique one solely on the basis of a careful examination of ordinary and scientific discourse is to rule out an importan avenue for bringing the relative, context dependen surce for accomplishing such an objective, namely, empirical psychology.

Achinstein's second argument against Carnap is closely related to the first. He argues that since theoretical entities can be referred to in observational reports, there can be no substantive distinction between observation and theory. But Achinsten's argument is again inconclusive since it is possible to account for such perceptual use theory and observation. The root of the inconclusiveness of Achinstein's argument is, I believe, his failure to take into account the possibility of theoretical accounts of the distinction which attempt to explain the

observational differences.
Finally, Achinstein argues, concede to Carnap both that perceptual usage is not a sufficient condition for identifying observationa example, electric fields they are not observable in themselves. Nevertheless, Achinstein maintains, the distinction is still contextdependent and not "the general sort required." But Achinstein nowhere specifies what he means by a "general sort of distinction", nor indeed why the Old Empiricists required it. What knd of diste distion dos Achinstein have in mind? A logical distervation and theory have to be of this sort? Would the distinction fail, if it were not logical but based o some physical laws of this universe, indeed, some physical laws about human knowers? Does any kind of context-dependence rule out the generality required by the distinction? Would a distinction based onction context of human cognitive capabilities imply that a unique distein between theory and obseration. 1 chall mintain shortly that these givestion can be answered in a way which helps define the kind of distinction which ought to be made and explain the context variations which Achinstein has documented.

Mary Hesse has criticized the Old Empiricist orthodoxy from another point of view. She has argued that since all predicates, observational as well as theoretical, depend in part on some oher gentral laws and theories, that there is no absolnty on the theory-dependent meaning and truth-value of observational predicates and propositions. Because 502 of this dependence, the application of observational predicates and observational classifications are sometimes changed in order to preserve
general laws. And since this is possible in-principle with regard to all
observation predicates, there is no irreplaceable set of observation predicates, there is no irreplaceable set of observation
predicates and propositions. However, she maintains against the predicates and propositions. However, she maintains against the testing and deciding between theories. Hesse concludes that "all descriptive predicates are theory-dependent or theory-laden in the sense that their correct application may become incorrect."

One does not need to dispute Hesse's account of the inter-dependence of observational statements on the one hand and classifications and general laws on the other. This seems to me to be correct. And Hesse's contention that observational predicates are in-principle replaceable also seems to me to be correct, though in need of interpretation which predicates and thus no substantial distinction between theory follows only if irreplaceability and/or no dependence on an expressions are necessary conditions for being an observation predicate. The Old Empiricists may have put such conditions on observation predicates. I shall argue that they are not necessary.

Irreplaceability does not seem to be a necessary condition for being an incomplete and not invariant $Y$ many observation statements are false, statements and their predicates observational More fundarvation replaceability or corrigibility is a function of a statement's truth-value and not its conceptual character. And it is the latter which is relevant to the distinction between theoretical and observational concepts. I shall try to clarify what $I$ mean by conceptual character in a few moments. I Sellars the principles of the com sense in which, what 1 shall call with which constitute them are irreplaceable. But such an and the concepts not a function of the truth and certainty of these principles. For they is not necessarily direct contacts with what is the case. Their irreplaceabilith is rather a function of the cognitive structure of the perceiving organism and its perceptual environment. Thus their irreplaceability is methodological rather than epistemological

As regards the dependence of observational concepts and thei Hesse herself argues that meaning is not only a function of cotentext but also of empirical association. It is this latter function which is important for the distinction I am making. Hesse argues quite rightly, I believe, that it is impossible to specify the necessary and sufficient conditions for the application of any alleged primitive predicates, since such an sufficient conditions of the newly introduced predicates ans sary and infinitum. Thus she concludes that we must arrive at a process which ad not be verbalized and in which a selection is made from the multiplicity 
of information available to the perceiver. And, as a result some information is lost. Hesse, of course, is not referring to any kind of the causal processes---to a large extent unconscious--which eventuate in the primitive categorizations of perceptual response. An account of these processes, she maintains, is a task for physiologists and psychologists. I agree, hough 1 belime a We can cons

We can conceive of the information-loss, referred to by Hesse, as hat a conscious, though non-verbalizable selection process is going on and some information is not included in the categorizing process. This information could possibly be retrieved under new circumstances and used for reclassification and correction or rejection of previous classifications. This is acceptable and the or inglity But there is another make use of this wa is of quite clear that part of the process of concept formation is unconscious and non-deliberative. This part is governed by the laws of physics, physiology, and psychology which provide a given viewpoint. These processes, no doubt, do not capture all the information in the situation. But the conceptual results of these causal processes, characteristic of the interaction of physical objecl, environanis, do possess a degree of psychologically structued hut of the biological species, man. Thus these concepts and the principles associated with them are invariant except under species mutation. But as long as it is not assumed that they capture all information and/or reflect in a direct way the perceived object and its environment, they are open to revision and change, especially by theories, even though we methodologically necessary. Thus we can argue for an

We can look at the point 1 am making in another way. If we distinguish with Aristotle that which is primary in the order of knowledge from that which is primary in the order of being, we can then argue for a primacy in the order of knowledge for these primitive concepts and principles, but not claim and theories depend on inserorder of knowledge, gentalizations referents of theories explain the abservational phenomena as causal effects or as phenomena manifestations. And if theories do tell us that certain things exist and what kind of things they are, then we can expect that in a completed theory they should explain the content of what we perceive. In this sense the meaning of dependence is from the top of he page te the mon explanans to explaned is is directed from the bottom of the page upward or from explananda to explanans. Thus there is a two-fold 504 dependence and independence. And the independence necessary to account for theory-free observations occurs in the order of knowledge. Therefore 1 conclude that Hesse's arguments against theory-free concepts, namely, that no concepts are invulnerable to criticism an replacement and that all concepts depend on lawlike generalizations, are inconclusive. I now move to my own positive accoun

My contention is that we need an epistemological theory of the New have failed to provide such a theory. The Old Empiricist" acceptance of an independent observation framework has been based on some form of the myth of the given or on a philosophical dogma abou the invulnerability of ordinary language. And the New Empiricist's relativization of the distinction between theory and observation has in scientific and ordinary discourse, an fysis of the distinction as made on an epistemological consideration of truth and meaning as in or only of Hesse. Neither approach is sufficient. My contention is that such theory can and should be developed, that there are substantial reasons for holding that there are theory-free concepts and that a theory can be constructed which can account for the varying usages we observe, especially the use of theoretical terms in perceptual reports.

ree conter some theoryWhat I have in mind is something similar to what Wilfrid Seliars has called the principles of the common sense framework or Manifest Image, though I believe that his implicit Old Empiricist presupposition finally subvert his attempts to give an account of this framework. ${ }^{9}$ The principles of the common sense framework are a set of propositions and relations. This is very vague: but I do not believe it is necessary or even possible at present to specify the exact content of these principles or list the theory-free concepts. On this point I agree whole-heartedly with Mary Hesse's remark that such a specification and list would be impossible until we have a completely adequate theory both of theory and of observation. The crux of my contention is that there is such a concers framework.

Drant to the Radicals as do the New Empiricists the basic correctness of (10) In-Principle Corrigibility, (11) to the New Empiricists I grant with some modifications the truth. And Relevant Meaning Independence and (15) Relevant' Truth-Value

Independence.
In distinction from the Old Empiricists, Radical Critics and New in the following sens: 
(16) Epistemic Givenness. They constitute an epistemic given. That is os say, they are a starting point in the order of knowledge. They are first They are the first cognitive results of the interaction of the human perceiving organism with its environment. But they reflect in no obviou way the cognitive structure of the perceiving organism or the structure of the perceptual object and its environment. Thus 1 reject as a myth any gase and (b) the assertion that the given is an extramental reality known with certainty.

(17) Biological Stability and Universality. Granted the biologica stability of the human species, we can assume in mature, health organisms a similar physiological and psychological structure. We also assume a general similarity in basic needs and tasks and some degree of which the human knoristy around in the world are the resut of an interaction of knower and known, we can assume some degree of universality in primitive conceptual structure.

(18) Evolutionary Products. This conceptual structure can be considered from the point of view of evolutionary theory as an evolutionary product. Thus it would be a-posteriori from the point of view of the species, though a-priori from the point of view of the fashion.

(19) Methodological Irreplaceability. This conceptual structure, though neither invulnerable to criticism nor irreplaceable because it is an absolutely accurate account of extramental reality, does possess stability which belongs to the biological make up of he human species. It will, relative to the (20) A Distinciton $B$

(hat the distinction Based on Physical Necessity. Thus we can argue in the sense that it is based on a physical necessity related to the basic physiological and psychological cognitive structure of the human perceptual apparatus. Consequently though it cannot be maintained that the distinction is a logical one, neither can it be claimed that it is

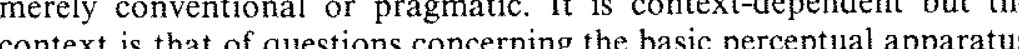
and achievements of the human perceiver. Of course, in a Humean perspective, within which ironically many of the New Empiricists still seem to work, where there is no necessity other than logical, the distinction I am making is matter of factual and/or empirical. But within "a broader perspective, one with which Aristotle would feel Edward

There is an increasing amount of evidence pointing to the perceptual adaptativeness of the human perceptual apparatus. The human perceiver seems to possess a twofold perceptual ability: (1) an ability to perceive wholes formulated in more or less theoretical or interpretative terms and (2) an ability to perceive in a more analytic way and in more fundamental terms."

It will be helpful to look briefly at an empirical psychological theory which makes use of this evidence. Jerome Bruner has proposed a theory
of perception which explains why and in what way concepts are available in our perceptual responses to the environment ${ }^{12}$ He contends that the accessibility of concepts is a function of both the fit between input and category specification and the perceiver's expectations and purposes. Perception, according to Bruner, involves an act of categorization which is accomplished by means of an inference from primitive categorization in which an object or event with cerss is a qualitative characterstics is isolated in experience. A further certain tion of clues leads to a more precise categorization in terms of the fit between clues and final categories and the expectancies and purposes of the perceiver. This process is not normally nor necessarily a conscious one, though it can be made so.

It is important to note that according to Bruner even the initial stage of perception is conceptual in character and that this corresponds to the
theory-free concepts which I have been discussing Thus though always present within the structure of perception because they are the initial cognitive results of the interaction between a structured environment and a structured perceiving organism, they are not necessarily present in perceptual repots. For the final perceptual report may be made in the perceptual use of heoretical terms whil

Consider a simple example. The nuclear physicist reports that he sees
the path of a proton in a cloud chamber. On the basis of Bruner's theory we can accept that report and yet not claim that the theory-observation distinction needs to be relativized. Moreover, limitations on the size of objects which can be seen by the human eye and the size of the proton of the water-droplets formed by the ionized particle is seen. The track of the initial stage of categorization within the perceptual process. Yet because of the expectancies and purposes of the scientist and the fit between initial conceptual clues and theoretical concepts, the scientist's perceptual report includes theoretical terms. On this basis we can accept theoretical terms and the possibility of developing varceptual use of the distinction between observation and theory without concluding for they do that the distinction is relative and context-dependent. issues which have been frequently confused to the detriment, I believe, 
of philosophical discussion. It distinguishes the conceptual as such from the theoretical. The former is the more inclusive category including both the theoretical and the observational. Il makes a distinction between perceptual and theoretical judgments while still being able to accoun or the use of theoretical terms in perceptual repons. It distinguishes questions of truth-value and corrigibility from questions concerning between an epistemic and ontological given. Thus it can reject the myth of the given and also show that the epistemic given plays a vita methodological role in our cognitive enterprises.

NOTES

More or less representative of this group are Carnap, Braithwaite, Hempel and Nagel. Polanyi. "Hesse, Achinstein, Suppe and Spector are important contributors to the new

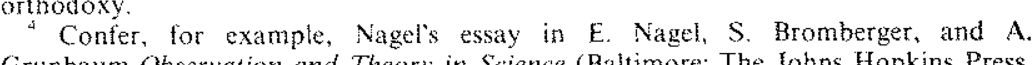
Grunbaum, Observation and Theory in Science (Baltimore: The Johns Hopkins Press,
1971). pp. IS-43. Also see Carl Kordig, "Observational Invariance," Philosophy of Science ${ }_{5}^{40}$ Numerous analyses and criticisms of the radical critics by both the Old Empiricists and the New Orthodoxy have appeared. Some of the most telling criticismos with respect to the Revolutions" Philosophical Review 73 (1964), pp.383-394, and "Meaning and Scientific Change," Mind and Cosmos. Ed. R. Colodny (Pittsburgh: Universily of Pittsburgh Press, Ond the present Status questions in The Structure of Scientifici Theories (Urbana, III: University of Illinois, 1974), 119-217.

-Confer Abner Shimony ls abservation Theory-Laden? A Problem in Naturalistic

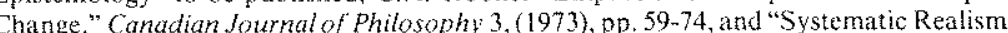
Synthese 26 (1974), pp. 408-497; Wilfrid Sellars "Scientific Realism or Irenic and M.W. Wartofsky, New York: Humanities Press. 1965. po. 171-204, and pasim in his books Science, Perception and Reality (New York: Humanities Press, 1963) and Science and Metaphysics: Wariations on Kantian Themes (New York. Humantites Press, 1968 . Vature and Function of Scientific Theories (Pittshurgh: University of Pittsburgh Pros, 1970), pp. 35-77; Peter Achinstein "The Problem of Theoretical Terms," American Phollosophical Q
Hopkins Press, 1968). ${ }^{8}$ Confer William Ro

"Belling is Seeing, Sometimes," New Scholasticism L (1976), Winter 1, to be publise, "Wvilfrid Sellars and the Demise of the Manifest Image,
"Confer William Rottschaefer, "W The Modern Shoolman, to be published, and Ordinary Knowledge in ing
Realism of Wilfrid Sellars, Ph.D. dissertation, Boston University, 1973.
Konrad Lorenz, "Kant's Doctrine of the A-Priori in the Light of Contemporary

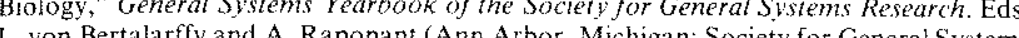
Research, 1961), pp. 23-35. Cf. Donald T. Campbell, "Evolutionary Epistemology," The Philosophy of Karl R. Popper. The Library of Living Philosophers, Ed. Paul A. Schlipg list section on evout tor A Reinterpretation and Reevaluation. Boston Studies in ihe Philosophy of Science, V. Vo. "i" Consult Shimony's paper cited above in note 6 . Humanities Press, 1971).

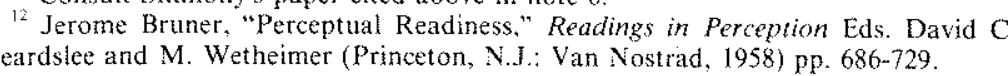

